\title{
The role of different impression methods for complete denture prosthodontics
}

\author{
Sara Nikoee Bazvand', Farshad Khamchin Moghaddam', Nazila Najari Dizaji² and \\ Shahin Shams Lahijani ${ }^{3 *}$ \\ ${ }^{1}$ Postgraduate student, Prosthodontics Department, Dental School, Shahid Beheshti University of Medical \\ Science, Tehran, Iran \\ ${ }^{2}$ Assistant Professor, Prosthodontics Department, Dental School, Qom University of Medical Science, Tehran, Iran \\ ${ }^{3}$ Assistant Professor, Surgery Department, Dental School, Qom University of Medical Science, Tehran, Iran
}

\begin{abstract}
The aim of the study was to determine dentist's desire for role of different impression methods for complete denture prosthodontics.The 1378 questioners form randomly distributed among dentists. The form included questions related about their idea for application and effect of boarder modeling materials in complete denture prosthodontics. Among the total forms, 657 forms fully filled, signature and returned by the dentists. Results: Acceding to the data, the highest percent of the dentists included in this study was graduated 11-15 years ago (28\%). Also, 73\% of the dentists always apply two complete dentures prosthodontics. 73\% of the dentists answered for always use administration of special trays. 64\% of the dentists answered that they always use impression before border modeling and $25 \%$ of them never use this. $89 \%$ of the dentists use compound material for border modeling. $64 \%$ of the patients use zinc oxide and eugenol (ZOE) and the 25\% use Alginate. Also, poly ether and poly sulfate were desired by 10.5 and $0.5 \%$ of the dentists, respectively. As seen there are different ideas among dentist for different impression methods for complete denture prosthodontics.
\end{abstract}

KEY WORDS: IMPRESSION METHODS, MATERIAL, COMPLETE DENTURE PROSTHODONTICS

\section{ARTICLE INFORMATION:}

*Corresponding Author:

Received 25 $5^{\text {th }}$ June, 2017

Accepted after revision $21^{\text {st }}$ Sep, 2017

BBRC Print ISSN: 0974-6455

Online ISSN: 2321-4007 CODEN: USA BBRCBA

Thomson Reuters ISI ESC and Crossref Indexed Journal

NAAS Journal Score 2017: 4.31 Cosmos IF: 4.006

๑ A Society of Science and Nature Publication, 2017. All rights reserved.

Online Contents Available at: http//www.bbrc.in/

DOI: $10.21786 / \mathrm{bbrc} / 10.3 / 12$ 


\section{INTRODUCTION}

An impression is a record, a facsimile of mouth tissues taken at an unstrained rest position or in various positions of displacement (Devan, 2005). In the case of an edentulous arch, this requires a unique combination of managing movable soft tissue commensurate with integrating different materials and a technique for accurate reproduction (Petrie et al., 2005). Stability of complete lower dentures has challenged dentists and patients alike. In particular, "flat lower ridge" is associated with difficulties in providing successful dentures (McCord et al. 1992). Resorption rates vary from patient to patient and some authors have postulated several etiological factors related to residual (alveolar) ridge resorption, ranging from localized pressure to systemic factors (Likeman, 1997). Making accurate final impression for complete dentures is a multistage process that involves a preliminary impression, a customized final impression tray and a final border impression (Zarb et al. 1990).

It is important to thoroughly examine the patient's mouth and select the most appropriate impression technique (Suenaga et al. 1997). A major requirement for final impression of complete dentures is to develop the peripheral contours to accommodate normal muscular function and to ensure peripheral adaptation without allowing air penetration between the future denture base and the mucous membrane (Daou, 2010). Differences are noticeable between the materials and methods currently used by dentists for final impressions in complete denture prosthodontics (Daou, 2010).

Even though the current generation of impression materials provides alternatives, making an initial impression still can be difficult when patients have significant resorption (Pyle, 1999). The concept of molding the periphery of complete denture prosthesis to the surrounding musculature has been accepted and taught for about past decades (Drago, 2003). Anecdotal evidence suggests that the impression techniques used in general dental practice may vary from those taught at dental schools (Drago, 2003). So, the aim of the study was to determine dentist's desire for role of different impression methods for complete denture prosthodontics.

\section{MATERIAL AND METHODS}

This cross sectional study was done using questioners on dentists during 2014-15. The 1378 questioners form randomly distributed among dentists. The form included questions related about their idea for application and effect of boarder modeling materials in complete denture prosthodontics. Among the total forms, 657 forms fully filled, signature and returned by the dentists. Then the data processed using excel software using Microsoft office ver. 2010 and presented as frequency and percent.

\section{RESULTS AND DISCUSSION}

The result of the different impression methods for complete denture prosthodontics is presented in figs. 1-6. The frequency of the dentists included into the study based on their years of graduate is presented in figure 1. As seen the highest percent of the dentists included in this study was graduated 11-15 years ago (28\%) and only $11 \%$ was graduated less than 5 years

The frequency of the dentists answer for application of 2 complete dentures prosthodontics is presented in figure 2 . As observed 73\% of the dentists always apply two complete dentures prosthodontics, initial and final while only $3 \%$ sometimes used this.

As seen in figure 3, 73\% of the dentists answered for always use administration of special trays and only $8 \%$ of the dentists never used special trays.

Also, 64\% of the dentists answered that they always use impression before border modeling and $25 \%$ of them never use this (figure 4).

Additionally, $89 \%$ of the dentists use compound material for border modeling while $11 \%$ of the dentists desire to use poly ether materials (figure 5).

Furthermore, 64\% of the patients use ZOF and the 25\% use Alginate. Also, poly ether and poly sulfate were desired by 10.5 and $0.5 \%$ of the dentists, respectively (figure 6).

As seen there are different ideas among dentist for different impression methods for complete denture prosthodontics. Also, there was different for materials used for complete denture prosthodontics among dentists. Since the last decade, several investigators have recommended using newer elastomeric materials such as polyvinylsiloxane and polyether for final impressions to replace the older and more traditional materials (Petrie et al., 2005). Four basic types of elastomer impression materials are currently in use in the dental profession such as silicone rubbers which polymerize by a condensation reaction, polysulfide (mercaptan) rubbers, polyethers and silicones which polymerize an addition reaction. The latter have been introduced relatively recently and are also called polyvinylsiloxanes (Lacy et al., 1981).

There are many materials for the final impression, such as gypsum, zinc oxide eugenol (ZOE) paste, polysulfide rubber, polyether, polyvinyl siloxane and alginate. Preferences vary much among dentists. However, there is no evidence that one technique or material produces better long term results than another (Duncan and Taylor, 2001). Many general practitioners use a single alginate impression as the definitive impression for 


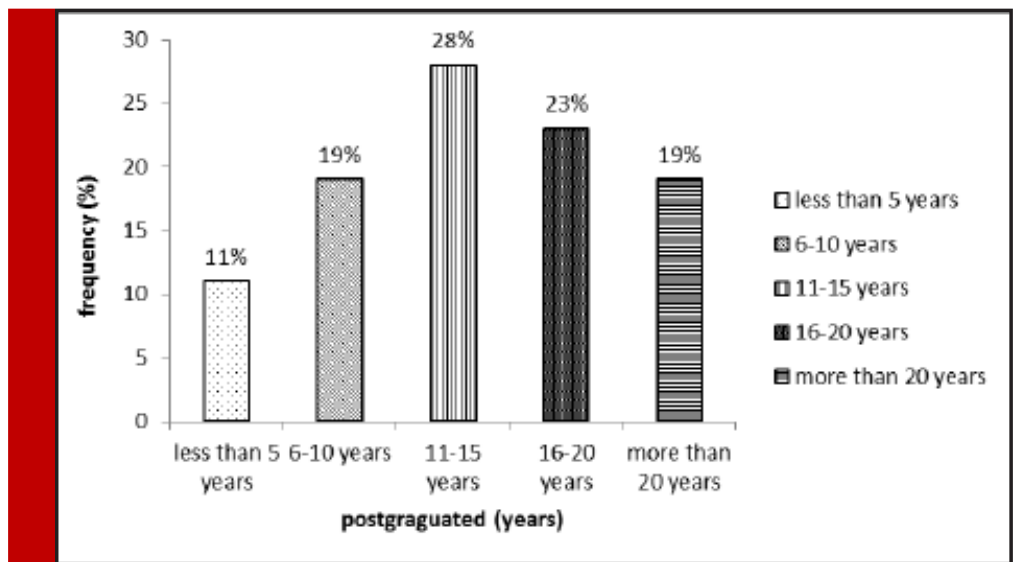

FIGURE 1 . The frequency of the dentists included into the study based on their years of graduate

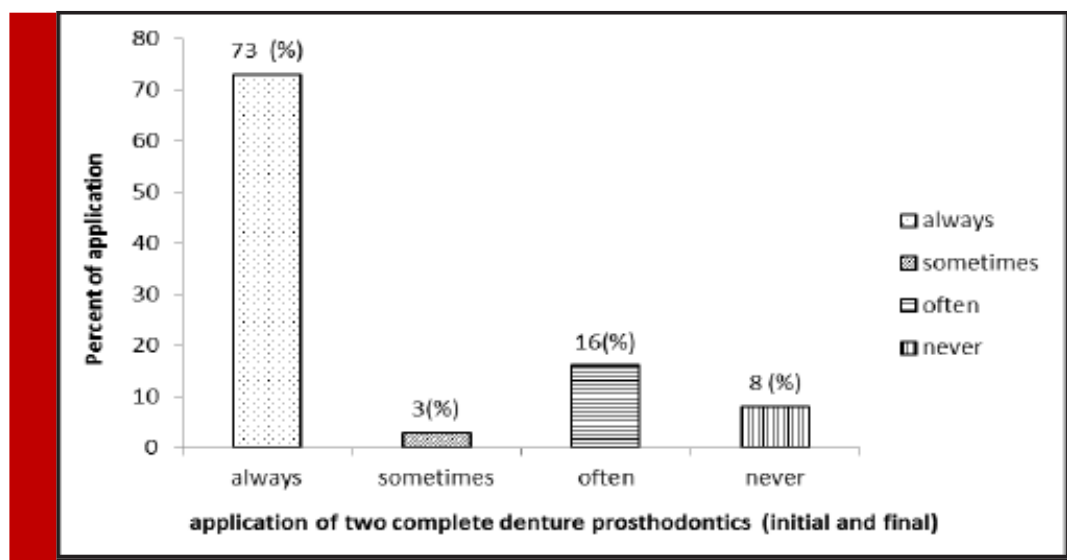

FIGURE 2. The frequency of the dentists answer for application of two complete dentures prosthodontics (initial and final)

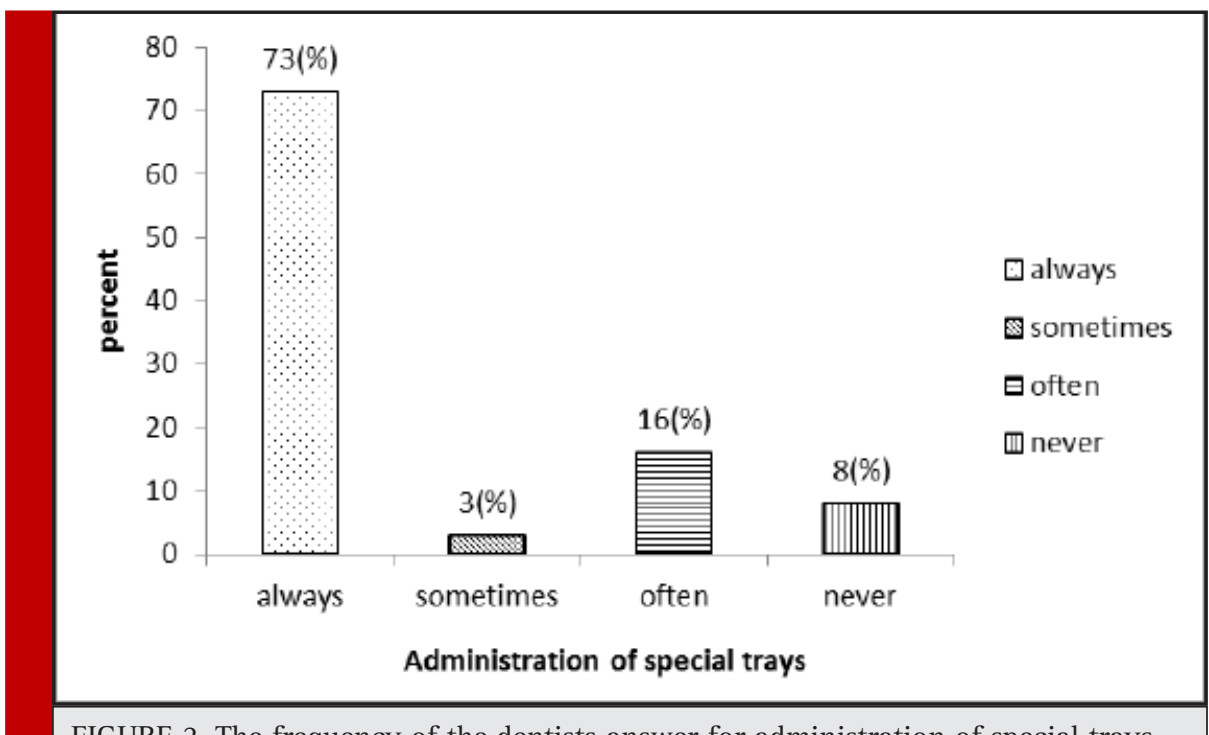

FIGURE 3. The frequency of the dentists answer for administration of special trays 


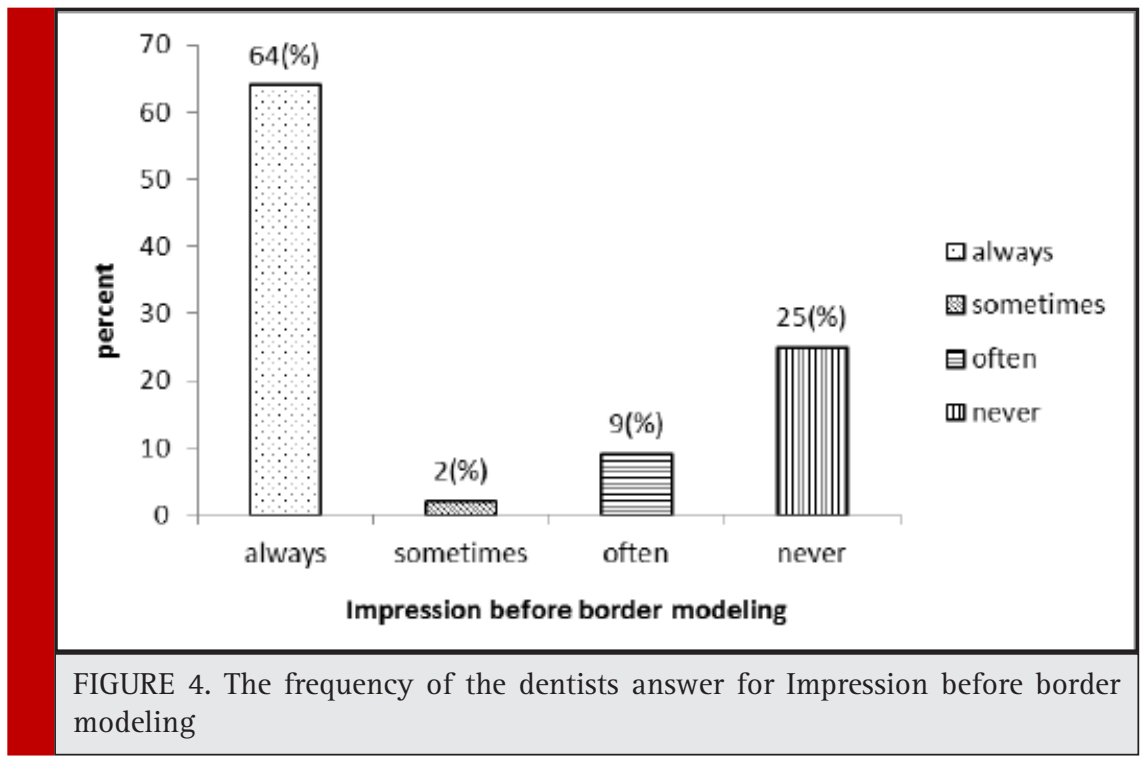

the construction of complete dentures, which conflicts with the teaching in practically all dental schools. It is, therefore, of interest that a randomized controlled trial found neither patient-assessed nor dentist-evaluated differences between dentures fabricated according to a traditional or a simplified method. The simple technique used alginate in a standard tray for the definitive impression, whereas the traditional technique included an individual tray with border molding and polyether for the final impression (Kawai et al., 2005). Although impression materials differ in many aspects and a variety of techniques exist in taking the impressions, there is no evidence to conclude that the clinical long-term outcome of dentures fabricated using varying materi- als and methods would differ significantly. These and other aspects of variation in methods and techniques are discussed in a review of an evidence base for complete dentures (Carlsson, 2006).

It is reported complete dentures fabricated with the conventional method that included a prelimi- nary impression made using alginate in a stock tray and subsequently a final impression made using silicone in a border moulded custom tray resulted in higher general patient satisfaction (Lepe et al. 2002). Currently, there are a number of issues with prosthodontic protocols that may provide underlying reasons why clinically significant differences are not produced in randomized controlled trial. Prosthodontic trials can have numerous

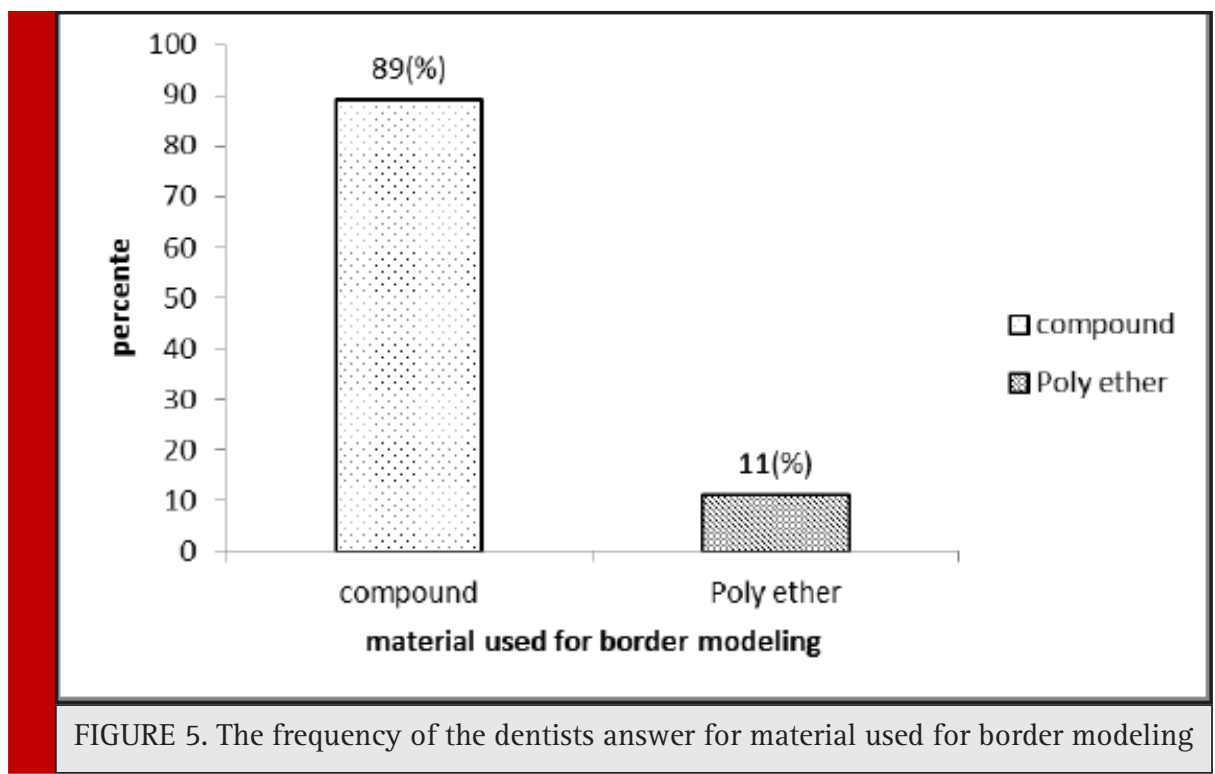


specific confounding variables such as patient related factors (ridge form, saliva flow, mucosal quality, patient expectation, psychological profile, perceived aesthetics), technical construction factors (occlusal form, impression technique, processing methods, different technicians/ technical procedures, the full use, or not, of the recorded sulcus depth) and dentist related factors (ability, education, number of clinicians, velocity of seating of the impression) (Dillon et al, 2008).

\section{REFERENCES}

Carlsson, G.E., 2006. Facts and fallacies: an evidence base for complete dentures. J. Prosthodont. 12, 280-287.

Daou EE. 2010 The elastomers for complete denture impression: A review of the literature. The Saudi Dental Journal 22, 153-160.

Devan, M., 2005. Basic principles in impression making. J. Prosthet. Dent. 93, 503-508.

Dillon S, Hyde TP, Brunton P.2008 A technique to construct duplicate dentures for clinical research. Quintessence Journal of Dental Technology 6:30-9.

Drago, C.J., 2003. A retrospective comparison of two definitive impression techniques and their associated postinsertion adjustments in complete denture prosthodontics. J. Prosthodont. 12 (3), 192-197.

Duncan, J.P., Taylor, T.D., 2001. Teaching an abbreviated impression technique for complete dentures in an undergraduate dental curriculum. J. Prosthet. Dent. 85, 121-125.
Kawai, Y., Murakami, H., Shariati, B., Klemetti, E., Blomfield, J.V., Billette, L. 2005. Do traditional techniques produce better conventional dentures than simplified techniques? J. Dent. 33, 659-668.

Lacy, A.M., Bellman, T., Fukui, H., Jendersen, M., 1981. Time dependent accuracy of elastomer impression materials. Part I: condensation silicones. J. Prosthet. Dent. 45 (2), 209214

Lepe, X., Johnson, G.H., Berg, J.C., Aw, T.C., Stroh, G.S., 2002. Wettability, imbibition, and mass change of disinfected low viscosity impression materials. J. Prosthet. Dent. 88, 268-276.

Likeman PR. Tongue control of lower complete dentures: a clinical hint. Br Dent J 1997;182:229-230.

McCord JF, Grant AA, Quayle AA. 1992 Treatment options for the edentulous mandible. Eur J Prosthodont Restor Dent1: 19-23.

Petrie, C.S., Walker, M.P., Williams, K., 2005. A surveys of US prosthodontists and dental schools on the current materials and methods for final impressions for complete denture prosthodontics. J. Prosthodont. 14 (4), 253-262.

Pyle, M.A., 1999. Impression technique for severely resorbed mandibles in geriatric patients. JADA 130.

Suenaga K, Sato T, Nishigawa G, Minagi S. 1997 Relationship between size of complete foundation area and resorption of alveolar ridge in the edentulous mandible. J Oral Rehabil;24:315-319.

Zarb AZ, Bolender CL, Hickey JC, Carlsson GE.1990 Boucher's prosthodontic treatment for edentulous patients. 10th ed. St Louis: C V Mosby. 